\title{
Aproximações em Design para além do Racionalismo: tecendo caminhos para o pluriverso
}

\section{Approaches in Design Beyond Rationalism weaving paths for the pluriverse}

\author{
Débora Andrade, Universidade Federal de Pernambuco \\ debora.andradeferreira@ufpe.br
}

\author{
María Cristina Ibarra, Universidade Federal de Pernambuco \\ cristina.ibarra@ufpe.br
}

\begin{abstract}
Resumo
O antropólogo Arturo Escobar (2016) conceitua a tradição racionalista como um contexto cultural onipresente em que grande parte do nosso mundo contemporâneo opera. Ele aponta essa tradição como responsável por moldar as formas de pensar e ser dos designers e da humanidade como um todo. O objetivo deste artigo é propor uma maneira de analisar práticas do design a partir de características da tradição racionalista apresentadas por dois autores reconhecidos e refletir como podemos superá-las, considerando que esta tradição tem produzido também consequências desastrosas. Para isso, apresentamos as características da tradição racionalista através de cinco monoculturas descritas pelo sociólogo Boaventura de Sousa Santos (2007) e quatro pilares da modernidade apresentados por Arturo Escobar (2018b). Em seguida, analisamos as relações entre estas características e metodologias e abordagens em design. Finalizamos mostrando alguns caminhos, no design, que buscam ou tentam escapar destas monoculturas e pilares do mundo moderno. Este artigo auxilia a compreender nosso lugar como designers e a perceber iniciativas mais ecológicas e pluriversais, nos termos de Santos (2007) e Escobar (2016), que estão sendo desenvolvidas no nosso campo. Estas reflexões são um primeiro passo para gerar impactos estruturais dentro da prática e pesquisa em design.
\end{abstract}

Palavras-chave: tradição racionalista, métodos em design, ecologias, pluriverso.

\begin{abstract}
Anthropologist Arturo Escobar (2016) conceptualizes the rationalist tradition as an omnipresent cultural context in which much of our contemporary world operates. He points to this tradition as responsible for shaping the ways of thinking and being of designers and humanity as a whole. The aim of this article is to propose a way to analyze design practices based on characteristics of the rationalist tradition presented by two recognized authors and to reflect on how we can overcome them, considering that this tradition has also produced disastrous consequences. For this, we present the characteristics of the rationalist tradition through five monocultures described by the sociologist Boaventura de Sousa Santos (2007) and four pillars of modernity presented by Arturo Escobar (2018b). Then, we analyze the relationship between these characteristics and methodologies and approaches in design. We conclude by showing some paths, in design, that seek or try to escape from these monocultures and pillars of the modern world. This article helps to understand our place as designers and to perceive more ecological and pluriversal initiatives, in the terms of Santos (2007) and Escobar (2016), which are being developed in our field. These reflections are a first step towards generating structural impacts within design practice and research.
\end{abstract}

Keywords: rationalist tradition, design methods, ecologies, monocultures, pluriverse. 


\section{Introdução}

O presente artigo faz parte dos resultados de um projeto de iniciação científica que se propôs a identificar abordagens metodológicas em design para além do racionalismo e ampliar o horizonte dos papéis das(os) designers na contemporaneidade. A nossa intenção, neste projeto, foi nos aproximar de uma prática de design mais relacionada com um mundo plural e em constante transformação.

Na pesquisa, percebemos como no design temos fortes influências do pensamento racionalista que promove hierarquizações no nosso campo e no mundo. Observamos como a maioria das abordagens metodológicas em design chegam a nós provenientes de países do Norte Global e que, apesar de serem pensadas para realidades divergentes das nossas, são ensinadas e aplicadas como se vivêssemos realidades bastante similares. Além da questão de hierarquização, também percebemos a falta de flexibilidade e a forte linearidade que está presente nas metodologias de design, que também são uma consequência da tradição racionalista. Estas características devem ser questionadas se queremos construir processos de design em correspondência com o entorno e o mundo.

Assim, este estudo começa com três questões de pesquisa: O que pensadores contemporâneos estão questionando sobre o racionalismo? Como o racionalismo se manifesta no design? Que abordagens metodológicas em design tentam escapar das monoculturas e crenças do racionalismo?

Os resultados deste projeto foram alcançados por meio do estudo de diferentes autores durante cerca de um ano de trabalho possibilitando uma melhor compreensão sobre o assunto. Após este período de revisão literária, utilizamos técnicas de arquitetura de informação como o cardsorting ${ }^{l}$ para resumir, esclarecer e ter um panorama geral das questões abordadas por cada autor. Para criar uma narrativa coerente e relacionar todas as informações coletadas, estas foram organizadas em uma tabela em que relacionamos as características da tradição racionalista com metodologias de design conhecidas. A partir destas relações, foram identificadas alternativas à tradição racionalista dentro do campo do design. Esse momento de arquitetar a estrutura do artigo foi essencial para ter um panorama geral das questões dos autores estudados e criar relações entre eles.

\section{Monoculturas e crenças da tradição racionalista}

Para o filósofo chileno Francisco Varela (1999 apud Escobar, 2018b), a sociedade moderna tem a tendência de se firmar naquilo que é formal, lógico e bem definido. Ela limita seu conhecimento sobre o mundo por vê-lo como um "mundo objetivo constituído por entidades que podem ser conhecidas, e portanto manipuladas e ordenadas" (ESCOBAR, 2018b, p. 112).

Essa ontologia moderna, ou seja, esta dinâmica do ser dentro do contexto da modernidade, tem bases na tradição racionalista (ESCOBAR, 2018b). O antropólogo colombiano, Arturo Escobar (2016) entende a tradição racionalista como um contexto cultural onipresente em que grande parte

\footnotetext{
${ }^{1} \mathrm{O}$ cardsorting é uma técnica de arquitetura de informação bastante utilizada no campo de $U X$ design, ou design da experiência do usuário. Essa técnica tem como objetivo evidenciar o conteúdo de uma pesquisa de forma compreensível. Cards com determinado conteúdo, descrições, adjetivos ou substantivos, são organizados em colunas, permitindo criar relações entre eles.
} 
do nosso mundo contemporâneo opera. Ele aponta essa "tradição" como responsável por moldar e orientar as maneiras de pensar e ser dos designers e da humanidade como um todo.

Para o sociólogo português Boaventura de Sousa Santos, essa racionalidade presente na sociedade moderna é reducionista, "preguiçosa, que se considera única, exclusiva e não vê a riqueza inesgotável do mundo" (SANTOS, 2007, p. 25). Ela, de acordo com este autor, se manifesta de diferentes formas, porém duas se ressaltam: a razão metonímica e a razão proléptica.

A razão metonímica é responsável por contrair o presente. Ela faz isso, pois "tem um conceito de totalidade feito de partes homogêneas, e nada do que fica fora dessa totalidade interessa" (SANTOS, 2007, p. 25). Ela toma uma parte da realidade existente no mundo e a considera como um todo, desconsiderando muitas realidades existentes. Já a razão proléptica é responsável por expandir o futuro, o enxergando como o definitivo e infinito progresso e desenvolvimento. Para Santos (2007), isso faz com que crie-se um futuro vazio e abstrato, que não se baseia no que está surgindo, mas que se firma em pensamentos utópicos. Com base nessas manifestações, Santos (2007) conclui que a racionalidade transforma o real sem o compreender. Ela não o compreende por excluir partes dele e faz isso por se basear em ideias como a simetria dicotômica. Segundo este autor, a dicotomia é responsável pela desclassificação de outros mundos ou realidades e por esconder sistemas hierárquicos.

Tendo por base os argumentos de Santos (2007), percebemos que a racionalidade é levada por conhecimentos dicotômicos: homem/mulher, norte/sul, natureza/cultura, entre outros. Essas dicotomias são vistas como totalidades do mundo real e não como partes de uma realidade bem mais ampla. Isso causa uma simplificação do mundo, além de levar a um sistema hierárquico, onde uma é colocada como dependente da outra e não pode agir no mundo fora do esquema préestabelecido pela outra parte.

A dicotomia e outras ideias redutoras presentes na sociedade moderna, podem ser observadas dentro dos pilares do mundo moderno, apresentados por Escobar (2018b) e nos modos de produção das ausências, de Santos (2007), que atuam como formas que impõem uma exclusão das realidades existentes no mundo. Juntos, esses pilares e modos introduzem características e comportamentos da tradição racionalista, sendo responsáveis por excluir realidades que estão presentes na sociedade.

Santos (2007) sintetiza a prática de exclusão de mundos em cinco modos de produção das ausências. Esses modos incentivam comportamentos baseados no fator redutor do racionalismo, o qual vê o que não existe, ou ainda não existe dentro da sociedade moderna, como impossibilidades e invisíveis à realidade hegemônica do mundo. Ele nomeia esses modos de monoculturas, por monoculturas serem responsáveis pela destruição de outros conhecimentos, reduzindo a realidade por descredibilizar conhecimentos alternativos e povos, cujas práticas são construídas a partir desses conhecimentos. Essas monoculturas são: a monocultura do saber e do rigor, a monocultura da escala dominante, a monocultura do tempo linear, a monocultura do produtivismo e a monocultura da naturalização das diferenças (Tabela 1). 


\section{Monoculturas}

\begin{tabular}{|c|c|}
\hline Monocultura do saber e do rigor & $\begin{array}{c}\text { Esta monocultura se baseia na noção moderna de que o único saber } \\
\text { rigoroso é o saber científico; portanto, outros conhecimentos não têm } \\
\text { validade nem o rigor do conhecimento científico }\end{array}$ \\
\hline Monocultura da escala dominante & $\begin{array}{c}\text { Esta monocultura reduz a realidade, pois toma como relevante apenas } \\
\text { o global e o universal, enquanto exclui o particular e o local }\end{array}$ \\
\hline Monocultura do tempo linear & $\begin{array}{c}\text { Esta monocultura determina que a história tem uma única direção e } \\
\text { que países desenvolvidos estão na dianteira }\end{array}$ \\
\hline Monocultura do produtivismo & $\begin{array}{c}\text { Esta monocultura segue a ideia de que o crescimento econômico e a } \\
\text { produtividade mensurada em um ciclo de produção determinam a } \\
\text { produtividade do trabalho humano ou da natureza. }\end{array}$ \\
\hline $\begin{array}{c}\text { Monocultura é a da naturalização das } \\
\text { diferenças }\end{array}$ & $\begin{array}{c}\text { Nesta monocultura, as diferenças causam um sistema hierárquico, pois } \\
\text { são tomadas como desigualdades, e aqueles que são inferiores, o são por } \\
\text { natureza }\end{array}$ \\
\hline
\end{tabular}

Tabela 1. Monoculturas apresentadas por Boaventura de Sousa Santos (2007). Fonte: Elaborada pelas autoras baseadas em Santos (2007)

De início, temos a monocultura do saber e do rigor que se baseia na noção moderna de que "o único saber rigoroso é o saber científico; portanto, outros conhecimentos não têm validade nem o rigor do conhecimento científico" (SANTOS, 2007, p. 29). Esta monocultura contrai o presente por excluir qualquer conhecimento fora das concepções científicas da sociedade (SANTOS, 2007).

Tim Ingold (2020), antropólogo britânico, aborda a temática da descredibilização do conhecimento popular em pesquisas de campo. Ele afirma que quando ouve-se famosos estudiosos falando, escuta-se com a esperança de aprender algo para aplicar nas experiências futuras, porém quando se conversa com pessoas comuns, o que elas dizem é tratado apenas como "evidência etnográfica do que [aquilo] diz sobre elas" (INGOLD, 2020, p. 2, tradução nossa). Os pesquisadores atribuem suas falas apenas a uma manifestação mais profunda de suas crenças e disposições culturalmente moldadas. Eles não dão validade ao saber daquelas pessoas.

Outra característica que essa monocultura engloba é a importância do rigor no processo de pesquisa. Ingold (2020), contudo, ressalta a negatividade dessa forma específica de rigor que é aplicada nesses processos. Para este autor, o rigor aplicado dentro da pesquisa moderna é privado de sentimento, não constrói experiências e "induz paralisia instantânea em qualquer coisa viva ou em movimento que possa entrar em contato" (INGOLD, 2020, p.2, tradução nossa). Esse rigor vem da consequência de ver um mundo não em formação, mas já formado, em que pode-se minerar uma informação para depois processá-la e formá-la em algo útil para a pesquisa em questão. Segundo este autor, com esse tipo de rigor não será possível obter a flexibilidade necessária para seguir as variações que ocorrem constantemente neste mundo em transformação. Por isso, ele propõe que o rigor não seja rígido, senão flexível, que possa acompanhar os fluxos do mundo.

A monocultura do saber e do rigor também erra por partir da noção de que a ciência independe do contexto ou da cultura na qual está inserida. Nas palavras de Santos, "não há ciência pura" (SANTOS, 2007, p. 23). Os diversos saberes alternativos que moldam uma comunidade importam, pois permitem que a pesquisa além de objetiva, não seja neutra. Não ser neutra significa tomar uma posição frente às injustiças da sociedade, utilizando as informações que possui para 
agir em prol da justiça e do bem estar do povo. A ciência, portanto, deve utilizar seus conhecimentos para impedir que poderes superiores utilizem sua influência para prejudicar o povo. Ela deve fazer isso tomando o cuidado de dialogar em vez de apenas impor uma nova ordem e se colocar como superior.

Seguindo adiante, temos a monocultura da escala dominante, que reduz a realidade, pois toma como relevante apenas o global e o universal, enquanto exclui o particular e o local (SANTOS, 2007). Ela faz isso a partir do universalismo, que valida toda ideia ou entidade independente do contexto na qual ocorre. Igualmente, temos a monocultura do tempo linear que determina que a história tem uma única direção e que países desenvolvidos estão na dianteira (SANTOS, 2007). O tempo deve nos levar ao futuro, que é construído com base nos comportamentos que se desenvolvem dentro desses países, portanto eles representam o progresso e o que países subdesenvolvidos, que são assimétricos com a realidade definida, devem almejar ser.

De acordo com Santos, a monocultura do produtivismo segue a ideia de que "o crescimento econômico e a produtividade mensurada em um ciclo de produção determinam a produtividade do trabalho humano ou da natureza" (SANTOS, 2007, p. 31). Com essa monocultura, a tradição racionalista ocidental exclui qualquer outra maneira de organizar a produtividade, pois as considera como maneiras improdutivas. É uma ideia que atinge, não somente os seres humanos e seu ciclo de trabalho, como também a natureza.

A última monocultura é a da naturalização das diferenças, nela as diferenças causam um sistema hierárquico, pois são tomadas como desigualdades, e aqueles que são inferiores, o são por natureza. Essa monocultura produz ausência por inferiorizar o que não se encaixa ao hegemônico (SANTOS, 2007).

Acrescentamos às monoculturas os 4 pilares do mundo moderno apresentados pelo antropólogo Arturo Escobar (2018b). Esses pilares são: a crença no indivíduo, no real, na ciência e na economia (Tabela 2). Ele utiliza a palavra "crença" para se referir aos pilares, para dar o entendimento de que não são a única maneira de pensar que existe, mas são formas historicamente específicas que aparecem como naturais ou superiores.

\begin{tabular}{|l|l|}
\hline \multicolumn{1}{|c|}{ Crenças/pilares } & $\begin{array}{c}\text { Com a crença no indivíduo nos vemos como seres independentes, vagando } \\
\text { por um mundo que gira independente de nós. É a ideia de que existimos como } \\
\text { seres separados e autônomos. }\end{array}$ \\
\hline Crença no real & $\begin{array}{c}\text { A tradição racionalista converte a existência de um mundo material na crença } \\
\text { de uma "realidade objetiva" ou "mundo externo" que preexiste às múltiplas inter- } \\
\text { relações que o constituem. }\end{array}$ \\
\hline Crença na ciência & $\begin{array}{r}\text { Como consequência da crença na ciência, tem-se criado uma hegemonia do } \\
\text { conhecimento moderno e desqualificação de toda outra forma do saber. }\end{array}$ \\
\hline Crença na economia & $\begin{array}{l}\text { A economia é considerada um domínio independente de pensamento e ação } \\
\text { que serve ao mercado, associado ao imaginário econômico de indivíduos que } \\
\text { realizam transações nos mercados, a produção, o crescimento ilimitado, o capital, } \\
\text { o progresso, a escassez e o consumo continuam sem obstáculos. }\end{array}$ \\
\hline
\end{tabular}

Tabela 2. Pilares do mundo moderno segundo Arturo Escobar (2018b) 
Com a crença no indivíduo nos vemos como seres independentes, vagando por um mundo que gira independente de nós (ESCOBAR, 2018b). É a ideia de que existimos como seres separados e autônomos. Essa ideia chegou com a modernização, e se impõe com a globalização neoliberal e a expansão dos mercados, dentro dos quais só podemos ser consumidores individuais.

A crença no "eu", estabelecida por esse primeiro pilar, conduz à crença no real. A tradição racionalista converte a existência de um mundo material na crença de uma "realidade objetiva" ou "mundo externo" que preexiste as múltiplas inter-relações que o constituem (ESCOBAR, 2018b). Todavia as "'realidades objetivas' e sólidas que aparentemente percebemos são o resultado das práticas concretas de muitos atores" (ESCOBAR, 2018b, p. 114). Essa crença cria uma atitude de dominação sobre a natureza dificultando uma verdadeira colaboração com a mesma, pois toma essa realidade como algo já formado que por ser conhecido, pode ser manipulado (ESCOBAR, 2018b). Essa racionalização de que conhecer algo o torna moldável é reforçado pelo terceiro pilar: a ciência.

Como consequência da crença na ciência, tem-se criado uma hegemonia do conhecimento moderno e desqualificação de toda outra forma do saber. Ela é grandemente responsável pelo domínio e violência exercidos sobre todos os mundos, principalmente os não modernos (ESCOBAR, 2018b). O psicólogo hindu, Ashis Nandy, ressalta que "a ciência não pode sequer dialogar com outras formas de conhecimento, uma vez que se atribui o monopólio do conhecimento, compaixão e ética" (Nandy, 1987, apud Escobar, 2018b, p. 10) .

Por último, Escobar (2018b) disserta sobre a crença na economia considerado um domínio independente de pensamento e ação que serve ao mercado. Para este autor é possível que a economia neoliberal tenha sido afetada pela crise de 2017-2018, porém o imaginário econômico de indivíduos que realizam transações nos mercados, a produção, o crescimento ilimitado, o capital, o progresso, a escassez e o consumo continuam sem problemas. Para Escobar (2018b), é a crença nesses pilares que causa uma operação de descontextualização, pois nos absolve de termos responsabilidade para com o mundo.

\section{A tradição racionalista e sua relação com o campo do design}

A tradição racionalista foi e é responsável, em grande parte, por contrair e ignorar a diversidade existente no mundo, promovendo a dominação de uma parte sobre o todo. Apesar da sua importância para o funcionamento de várias áreas do saber, a racionalidade tem causado impactos prejudiciais em diversos meios profissionais. Nesta seção, serão apresentadas ligações entre conceitos da tradição racionalista com características de algumas metodologias e abordagens em design. Começamos com uma breve análise de simetrias dicotômicas no design, como passado/futuro, norte/sul, e mente/corpo, e seguimos com uma reflexão sobre as monoculturas (Santos, 2007) e os pilares do mundo moderno (Escobar, 2018b) refletidos no campo do design.

Metodologias têm um forte papel dentro do campo do design. Elas funcionam como uma estrutura de passos a serem seguidos para chegar a um resultado final em um projeto. Elas são instrumentos que ajudam designers em seus processos de criação. Todavia, devido a influências do racionalismo, elas, por vezes, se tornam uma trava que limita a visão dos designers para a diversidade existente no mundo.

O designer alemão Gui Bonsiepe (2012), no livro 'Design como prática de projeto', apresenta o que ele chama de "metodologia clássica", um grupo de metodologias majoritariamente elaboradas na década de 60, que buscam racionalizar o processo de design. Essa metodologia 
determina uma ordem sequencial lógica de passos a serem tomados pelos designers para chegar a um produto final. Ela, no entanto, segundo este autor, toma essa mesma sequência de etapas para qualquer problema e em qualquer contexto. Ignorando diferenças e temas que hoje são de demasiada importância, como os limites do crescimento, a poluição, a crise energética, o desemprego em massa, a distribuição de renda, entre outros.

Apesar das limitações produzidas por essas reduções de realidades, esta "metodologia clássica" se impõe como um processo universal, neutro e atemporal. Podemos relacionar isso, com os argumentos do designer e pesquisador português, Mário Moura. Ele afirma que:

$\mathrm{O}$ universalismo, a neutralidade e a intemporalidade do design mantêm-se porque cumprem funções importantes para a identidade do design. Prometem uma economia metodológica, garantindo que se possa usar o mesmo processo em todos os contextos e épocas. Asseguram a coesão interna da disciplina, aplainando as diferenças existentes entre os praticantes. Certificam a durabilidade das soluções encontradas, que assim se distinguem, aos olhos dos praticantes, dos caprichos da moda. (MOURA, 2018, p. 42)

Nomear uma metodologia como universal e atemporal garante que ela se manterá assim. É uma forma de assegurar o domínio dessa metodologia sobre as outras. Infelizmente, como visto anteriormente, é esse domínio que causa a exclusão de muito do que existe. Estabelecer esse domínio sobre a forma de criar e desenvolver no presente, nos leva ao próximo ponto que é a ilusão do controle sobre o futuro.

Como campo de estudo, o design se volta predominantemente para o futuro, afinal, os profissionais da área mantêm seu foco na criação de intervenções que levam à mudança (KJAERSGAARD et al, 2016). Contudo, por se voltarem para o futuro, designers influenciados pela tradição racionalista deixam para trás o passado, não refletindo nem sendo sensíveis a tudo que está contido nele (ANUSAS, HARKNESS, 2016). Por contrair seu horizonte temporal, alguns designers tendem a mudar o mundo sem compreendê-lo. Por faltar essa reflexão no passado, e também no presente, o futuro que está sendo desenvolvido se torna um futuro vazio, pois se baseia em ideias abstratas e não no que está surgindo, como nos sugere Santos (2007).

Os autores do livro Design Anthropological Futures (2016), acreditam que muitos profissionais são levados a enxergar o futuro como singular, em vez de algo diversificado, que pode conter diversas ideias e formas de viver. Isso não quer dizer que não pensem em futuro(s) alternativo(s), mas que coloquem um futuro como dominante sobre outros. Essa dominação de um futuro sobre outros se origina a partir de uma visão dicotômica do mundo. Como foi apresentado na seção anterior, essa dicotomia é responsável por desclassificar outros mundos e também, por estabelecer uma hierarquia. Dentro do design, isso fica claro quando nota-se que uma metodologia/forma de proceder ou um futuro está ocupando uma posição de dominância sobre os outros.

Essa visão dicotômica presente dentro do design, possivelmente se origina da dicotomia do Norte/Sul. Os países do Norte Global, que são caracterizados por possuir maior capital e desenvolvimento tecnológico, estabelecem metodologias que são tidas como universais e atemporais, mas que provavelmente não consideram diferenças geográficas e sócio-políticas. Isto faz com que países chamados periféricos, ou seja, do Sul Global, sejam pressionados a se moldar de acordo com o cenário dos países 'centrais' se quiserem alcançar a ideia de progresso, que também é estabelecida pelos países do Norte Global.

Bonsiepe (2012) esclarece o relacionamento do Norte e Sul Global utilizando as duas formas de paternalismo. O primeiro é o paternalismo benevolente, que apesar de bem-intencionado continua a ser paternalismo. Nele, alternativistas procuram desenvolver soluções para os países 
'periféricos' a partir dos países 'centrais' (BONSIEPE, 2012). Esse comportamento conduz a criação de soluções sem a verdadeira compreensão da situação que o outro vive, tornando-se uma solução vazia, que retira o direito que os países periféricos têm de criar o seu próprio futuro.

A segunda forma de paternalismo é o paternalismo maquiavélico, "que engendra todas as manobras possíveis para evitar que o submundo periférico tome consciência de sua condição e possa trilhar um caminho próprio para escapar do subdesenvolvimento." (BONSIEPE, 2012, p. 98). Isto impede a quebra das dicotomias, pois fortalece a ideia de que apenas existem duas formas de ser (Norte e Sul) e determina que o relacionamento entre essas duas partes vai ser hierárquico. Simplificando a realidade e dificultando o desenvolvimento de outras possibilidades.

Antes de dar seguimento, é necessário expressar que reconhecemos que Bonsiepe, apesar de possuir ideias relevantes para um discurso que promove um design para além do racionalismo, ainda se encontra em um âmbito responsável pela proliferação da tradição racionalista no meio do design, por exemplo, por utilizar termos como países desenvolvidos e subdesenvolvidos, centrais e periféricos, clássico e alternativo, entre outros.

Dando continuidade a visão da simetria dicotômica dentro do design, pode-se observar a separação de mente/corpo, uma característica do pensamento racionalista apontado por Escobar (2018b). É possível observar essa separação no formato da metodologia que o designer italiano, Bruno Munari (1998), apresenta no livro 'Das coisas nascem coisas', e que é usado em escolas de design brasileiras até hoje.

Por causa do receio que Munari (1998) tem de dar espaço para o erro, ele afirma que sketches e modelos de um produto devem ser feitos apenas no final de todo o processo para diminuir a possibilidade de falha ao máximo. Entendemos que essa fase, para Munari, é apenas de representação do que o produto será e não de ideação do mesmo. Por não utilizar o corpo junto à mente como um caminho para a reflexão durante o processo criativo desde o início, os designers perdem o benefício da união dessas duas esferas para uma melhor compreensão e expressão do mundo ao redor.

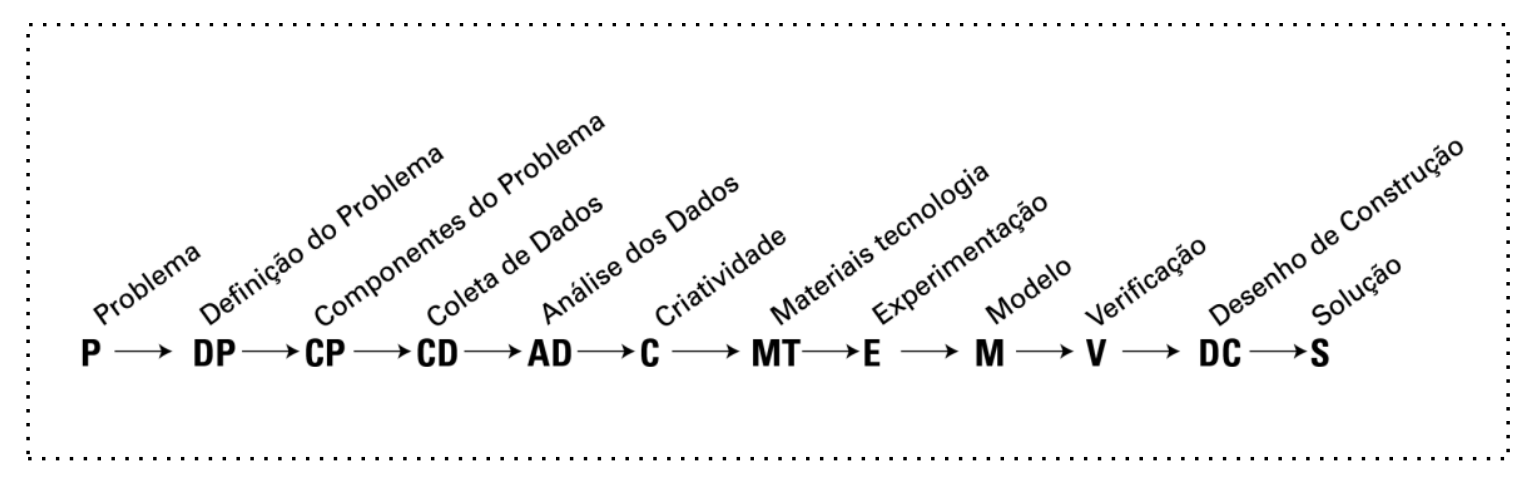

Figura 1: Metodologia de Projeto de Bruno Munari. Fonte: Elaborada pelas autoras adaptado de Munari (1998)

\section{Análise das monoculturas no campo do design}

Dando continuação, analisaremos como as cinco monoculturas que Santos (2007) introduz e que identificamos dentro do campo do design.

Em relação à monocultura do saber e do rigor, temos como exemplo a "metodologia clássica" criticada por Bonsiepe (2012), que apresenta um perfil absolutista, ou seja, se considera sem limitações ou restrições, se impondo como uma metodologia que funcionaria em qualquer contexto. Essa metodologia, e outras que se assemelham nesse aspecto, contribuem para a 
diminuição da diversidade e pluralidade de saberes e formas de fazer design, além de ignorarem a autenticidade do processo de criação de diversas comunidades.

Podemos argumentar que, por não serem atuais, talvez esse conjunto de metodologias clássicas não sejam tão utilizadas como antes foram. No entanto, outras metodologias e abordagens estão estabelecendo sua própria dominação sobre a área. Vemos, por exemplo, o Design Thinking ${ }^{2}$ e o método Agile $^{3}$, que se apresentam como a face da inovação e a nova forma de fazer design e, assim como as outras, criam uma dominância na área e contribuem para a desvalorização de outras formas de fazer design. Será que o Design Thinking é uma metodologia que pode ser usada em qualquer contexto?

Acrescentando ao perfil absolutista, o receio ao erro, apresentado por Munari (1998) no seu livro, é outra característica dessas metodologias que se encaixa com a monocultura do saber. Esse receio limita a exploração de outras opções, pois assim que designers, orientados por práticas racionalistas, obtêm uma metodologia que funcione, outras possibilidades são muitas vezes desconsideradas e descredibilizadas sem serem propriamente testadas e exploradas. Isso limita o potencial de criação de designers e estabelece um comportamento rigoroso e mecanizado durante o processo. Podemos relacionar esse comportamento à racionalidade preguiçosa apresentada por Santos (2007), que reduz o mundo para não passar pelo longo processo de descobri-lo e buscar compreendê-lo.

Continuando com a "metodologia clássica" como exemplo, seguimos para a monocultura da escala dominante. A "metodologia clássica" que Bonsiepe (2012) apresenta e muitas outras metodologias foram e são estabelecidas por países do Norte Global, sendo aceitas por países do Sul Global sem o necessário questionamento. Elas, muitas vezes, apresentam um perfil absolutista prejudicial, ignorando diferenças importantes entre diferentes contextos. Por ignorá-las, essas metodologias estabelecem uma forma de proceder para o Sul Global a partir do Norte Global, controlando a maneira como esses países configuram suas formas de ser.

Chegamos à monocultura do tempo linear que leva à visão que existe apenas um caminho na história e que os países desenvolvidos se encontram na dianteira (SANTOS, 2007). Bonsiepe (2012) demonstrou que alguns países do Norte Global podem se posicionar como se já conhecessem o futuro e qual é o caminho que outros países devem percorrer para chegar até eles. Então, utilizando do "paternalismo" (BONSIEPE, 2012), guiam os países chamados periféricos por esse caminho. Isso implica que os países do Sul Global sempre estarão na retaguarda, pois lhes é fornecido apenas um caminho para chegar ao suposto progresso, e como este já foi percorrido pelos países do Norte Global, os que já estão na dianteira sempre permanecerão nela.

Podemos também perceber a ação desta monocultura no cenário que o designer Mike Anusas e a antropóloga Rachel Harkness apresentam no capítulo "Different presents in the making" do livro 'Design Anthropological Futures'. Eles falam da criação e do design em um presentepróximo (close-present). Nele, a concepção do tempo é vista como uma particularização linear, as experiências diárias com o tempo se tornam contraídas e há pouca reflexão sobre o passado, por causa da maior orientação ao futuro (Figura 2). E mesmo esse futuro é visto como eventos que estão prestes a acontecer (ANUSAS, HARKNESS, 2016). De acordo com estes autores, essa compreensão do tempo leva a um ambiente de trabalho infectado por pressão, tensão e expressões

\footnotetext{
${ }^{2}$ É um processo para solução de problemas de forma criativa que propõe um design centrado em humanos. Foi popularizado pelo fundador da IDEO, David Kelley.

${ }^{3}$ É um processo criado para o desenvolvimento de softwares que busca a solução de problemas se baseando em um desenvolvimento iterativo e utilizando da colaboração com os "stakeholders".
} 
verbais que levam ao entendimento de que o tempo é curto e não está sob o controle dos designers, criando um ambiente de trabalho individualista e mecanizado.

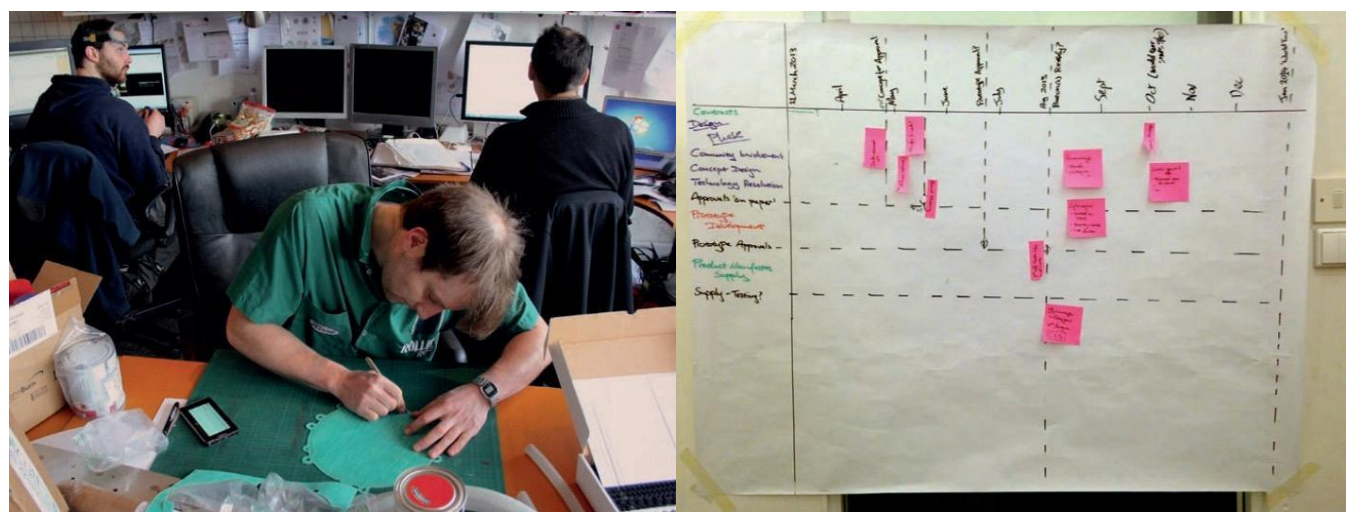

Figura 2: a) Um ambiente de trabalho típico de um estúdio de design de produto no Reino Unido. b) Linha do tempo do projeto mostrando uma progressão linear, da esquerda para a direita, por meses. Fonte: ANUSAS, HARKNESS, 2016

Seguimos para a monocultura do produtivismo, na qual a produtividade do trabalho humano ou da natureza são determinados pelo crescimento econômico e avaliados utilizando como base um ciclo de produção (SANTOS, 2007). Isso pode ser notado, quando observamos que dentro de uma realidade orientada pelo racionalismo, designers veem a natureza e o ser humano como duas esferas divergentes e por isso não consideram a 'natureza' quando pensam na produtividade para o ser humano.

Observando o comportamento dos designers dentro de um cenário de criação do presentepróximo (close-present), notamos a falta de um alto nível de "consciência ecológica" (ANUSAS, HARKNESS, 2016, p. 65). Dentro de seu meio de trabalho, eles visam criar objetos para promover um crescimento econômico e não um crescimento em seu pensamento ecológico (ANUSAS, HARKNESS, 2016). Mesmo quando se fala de design ecológico, isso é apenas uma nova metodologia aplicável ao design de produto, que ainda é subordinada a uma perspectiva de temporalidade contraída do presente próximo (close-present) (ANUSAS, HARKNESS, 2016). O que importa nesse cenário é satisfazer aos desejos do cliente e não acabar com a dicotomia de produtividade de humano/natureza. Explicaremos melhor estas afirmações na seção 'Abordagens para além do racionalismo', quando refletirmos sobre a ecologia das temporalidades.

Por último, analisando a monocultura da naturalização das diferenças trazemos à tona as reflexões apresentadas pelo crítico de design português Mário Moura (2018) sobre design e gênero, que levou ao design ter que passar por um processo de masculinização para ser creditado. Moura (2018), utilizando do discurso de Paul Rand, mostra como a arte e o design, no início ${ }^{4}$, eram considerados campos 'afeminados' ${ }^{5}$. Então, para dar crédito ao design e este ser 'valorizado', "foi essencial afastá-lo de conotações domésticas" (MOURA, 2018, p. 36), foi necessário masculinizá-lo. Segundo este autor, disso, veio a necessidade do distanciamento da arte e do design e o estabelecimento de ateliês e estúdios, com o intuito de distanciar o design do ambiente doméstico, que é majoritariamente e de maneira sexista, associado a atividades femininas. Com isso é possível observar a presença da dicotomia homem/mulher e da hierarquização intrínseca nesse relacionamento. Também vemos como esse pensamento influencia diretamente o

\footnotetext{
${ }^{4}$ No texto de Moura (2018), não é claro exatamente quando isto veio a acontecer. Ele está se referindo a antes da institucionalização do design em Portugal, no final da década de 1960.

5 Termo usado por Paul Rand. Para Moura (2018), esta palavra está falando da conotação que o design tem com a homosexualidade, percebida de modo depreciativo como feminização.
} 
comportamento de muitos designers, gerando até uma aversão à arte e à falta de dignidade atribuída a trabalhos home office.

\section{Análise dos pilares do mundo moderno no campo do design}

Percebendo comportamentos dentro do campo do design é possível fazer relações entre eles e os quatro pilares do mundo moderno de Escobar (2018b) que são: a crença no indivíduo, no real, na ciência e na economia.

Em relação à crença no indivíduo e à crença no real, Escobar (2018b) afirma que grande parte da prática do design está baseada nelas. Isso acontece quando o design objetifica o mundo, ou seja, quando transforma a experiência em uma 'realidade objetiva'. Quando objetificamos o mundo, estamos dispostos a dominá-lo. A crença no indivíduo destrói as formas de relação comunitárias e a ideia da interexistência. O conceito de interexistência está relacionado com a noção de ontologia relacional em que as coisas não existem, elas inter existem. A flor inter-existe com a planta, a água, o solo, os insetos polinizadores, etc. A crença no real, incentiva o olhar objetificador que não só os designers podem ter, mas qualquer profissional que veja o mundo como uma grande reserva de recursos naturais. Podemos pensar que a crença no indivíduo não é uma questão de designers, pois eles aprendem a trabalhar em grupo e se relacionam com diversos profissionais em seus projetos. Porém, Escobar (2018b) vai muito além do trabalho em grupo e nos faz refletir sobre o resultado do design e as formas como designers se relacionam com nãohumanos.

A crença na ciência se assemelha à monocultura do saber e do rigor de Santos (2007) e como foi visto na seção anterior, está fortemente presente no campo do design. Em relação à crença na economia, voltamos nossos olhos para o cliente do design que, de acordo com Munari (1998), seria a indústria. É ela que está determinando os problemas dos quais os designers deverão se ocupar. Assim, por servir à indústria, os designers baseiam sua produtividade em questões econômicas. Anusas e Harkness (2016) argumentam que dentro de um ambiente de criação de presente-próximo (close-present), designers focam em criar produtos que contribuam para o crescimento econômico. Assim, percebe-se como a produtividade dos designers entra em um ciclo de produção que segue o da economia. Como podemos escapar desse ciclo e entrar em outras esferas que não são necessariamente 'econômicas'?

\section{Abordagens para além do racionalismo}

Continuando com estes dois autores e com as teorias que trazem em relação ao racionalismo, apresentaremos uma aproximação ao que chamamos de abordagens para além do racionalismo. Aqui, traremos algumas maneiras de abordar os processos de design que consideramos buscar ou tentar escapar das monoculturas e crenças apresentadas por Santos (2007) e Escobar (2018b), respectivamente.

Após mostrar as monoculturas do saber, Santos (2007) indica o que ele chama de ecologias, isto é, a contraposição das monoculturas. Elas são: Ecologia dos Saberes, da Transescala, das Temporalidades, das Produtividades e do Reconhecimento. Exploraremos o que são e como podemos observá-las no design.

Iniciando pela ecologia dos saberes, Santos (2007) busca possibilitar que o saber 'laico' e o científico possam dialogar. Assim, o saber científico não se apresentaria como uma monocultura, mas como parte de uma coleção diversa de saberes. Santos (2007, p. 33) afirma que "o importante 
não é ver como o conhecimento representa o real, mas conhecer o que determinado conhecimento produz na realidade".

A partir dos anos 70, surge na Escandinávia o design participativo. Este tipo de design busca envolver os chamados usuários dentro do processo de design, apontando a uma horizontalidade nesse processo de tomada de decisões. Esta abordagem pode ser reconhecida em diferentes países e regiões do mundo. Na América Latina, identificamos que designers têm se inspirado em Paulo Freire, pedagogo pernambucano (SERPA et al, 2020) e em Orlando Fals Borda, sociólogo colombiano (IBARRA, 2020), na busca por um design mais dialógico e sentipensante, aberto ao que os participantes têm para contribuir com o processo.

Essa ecologia também pode se relacionar com a crítica que Escobar (2018b) faz à crença no indivíduo, na ciência e no real, pois ela clama por uma coletividade, por uma ampliação dos saberes e aceita como o modo como nos relacionamos e vemos o mundo, impacta a realidade em que vivemos (SANTOS, 2007).

Santos (2007) apresenta a ecologia da transescala como "a possibilidade de articular em nossos projetos as escalas locais, nacionais e globais" (SANTOS, 2007, p. 36). Escobar (2018a), citando Manzini, afirma que dentro de um cenário de design é possível enxergarmos um design que construa a união do local e do global, trazendo a produção para mais perto do consumo. Escobar (2018a) apresenta essa possibilidade dentro do Design de Transição, que faz conexões entre visões de transição com o design. A Transition Town Initiative ou TTI, é uma proposta de uma transição para uma sociedade que funciona com base em uma relocalização de mantimentos e tomadas de decisão, possibilitando que o que pode ser produzido localmente o seja (ESCOBAR, 2018a).

Com a ecologia das temporalidades, Santos (2007) procura estabelecer que existem outros tempos além do tempo linear. Anusas e Harkess (2016) trazem essa ideia para o design com a introdução do presente de longo alcance (far-reaching present). Dentro desse cenário de criação, o senso do agora conecta tempos, pessoas e lugares, e cresce com a possibilidade da diferença enquanto está ciente do que está por vir (ANUSAS, HARKNESS, 2016). Nesse processo, os materiais utilizados são retirados de um esquema linear convencional de tornar matéria-prima extraída em desperdício, e é dada continuidade à sua existência.

Santos (2007) apresenta a ecologia das produtividades como consistindo na "recuperação e valorização dos sistemas alternativos de produção, das organizações econômicas populares, das cooperativas operárias, das empresas autogestionadas, da economia solidária, etc" (SANTOS, 2007, p.36). Podemos utilizar novamente a TTI como exemplo, pois é uma construção de comunidades partindo de um projeto coletivo de design, propondo uma re-imaginação do funcionamento de comunidades em relação à produção, economia e política (ESCOBAR, 2018a).

Como parte do design autônomo, Escobar (2018a) entende que todas as comunidades praticam design nelas mesmas e por fazerem isso criam um sistema de aprendizado sobre si. Criando também formas próprias de viver. Inspirando-se em Manzini, Escobar (2018a) acredita que designers fariam parte de criar condições para mudança social colaborativa, sendo facilitadores, dando apoio aos projetos individuais e coletivos de uma comunidade.

Voltando ao cenário de presente de longo alcance (far-reaching present), Anusas e Harkness (2016), também mostram como o design poderia ser aplicado em comunidades e por comunidades repensando e dando espaço para sistemas alternativos de produção e construção. Harkness, trabalhou como construtora voluntária de eco-casas (earthships) feitas por membros da comunidade de uma forma participativa e ecológica (Figura 3). Os construtores moldam seus 
horários de trabalho no projeto para fluir com suas vidas diárias, com o clima e as estações do ano. Para eles, o conceito do agora se estende e conecta tempos, lugares, pessoas e se preocupa com o que está por vir sem esquecer o que veio anteriormente. As casas também funcionam seguindo não o ciclo dos seus moradores, mas dos recursos renováveis que utilizam, ou seja, se conectando com o ambiente (ANUSAS, HARKNESS, 2016).

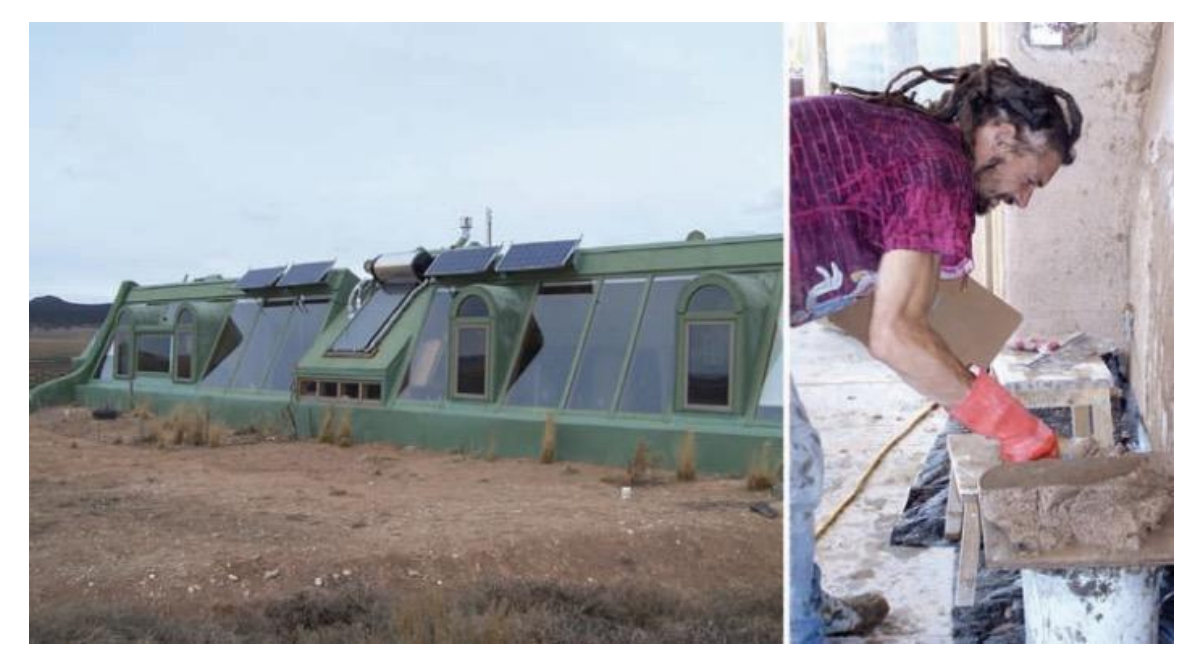

Figura 3: Earthships construídas em Novo México (2006). Fonte: Anusas e Harkness, 2016

Concluímos as ecologias com a ecologia do reconhecimento. Com ela, Santos (2007) propõe que busquemos reconhecer nas diferenças o que é produto de hierarquia e o que não é. Então, só depois de retirar as diferenças que se baseiam em um processo hierárquico, que aceitaremos as diferenças que restarem.

É importante ressaltar que os exemplos expostos aqui são uma amostra do que está acontecendo no campo do design. Utilizamos as ecologias como um tipo de lente que nos ajuda a compreender melhor estas iniciativas e valorizá-las. Igualmente, percebemos esta análise como um convite para continuar e intensificar a proliferação destas práticas no design.

\section{Considerações finais}

Nosso objetivo com este artigo é criar um caminho para formas de fazer design que procuram reconectar esferas que a modernidade e a tradição racionalista têm separado, trançando as bases para a construção de um design mais ecológico, nos termos de Santos (2007), ou seja um design menos preguiçoso, ausente e excludente, que abrace o pluriverso (Escobar, 2016, 2018a, 2018b) e esteja atento ao seu redor (Ingold, 2020).

Tivemos a intenção de tecer diferentes linhas de pensamento, construindo um tipo de manifesto que abra caminhos para pensar design de pontos de vistas diferentes, se conectando mais com o local e se desligando pouco a pouco da matriz eurocêntrica. Buscamos assim, nos aproximar de formas decoloniais de fazer design.

Com a finalização desse projeto conseguimos observar o impacto claro do racionalismo dentro do design. No artigo, questionamos algumas propostas metodológicas do designer italiano, Bruno Munari (1998). Nossas conclusões também foram fortalecidas com as coletas das críticas que Bonsiepe (2012) fez a essas "metodologias clássicas". 
Consideramos que a revisão bibliográfica foi essencial para o êxito do estudo, pois proporcionou uma maior confiabilidade e certidão nos resultados. As técnicas utilizadas para a arquitetura das informações, como o cardsorting e a tabela para cruzamento de dados, auxiliaram imensamente na estruturação do artigo e têm forte potencial para serem utilizadas em futuros processos de pesquisa.

A maior contribuição deste artigo é a apresentação de uma lente que nos auxilia a compreender nosso lugar como designers e a perceber com maior facilidade, abordagens e iniciativas que estão proliferando no design atualmente, no meio de uma crise sócio-ambiental. Procuramos, assim, reforçar essa conversa sobre o assunto da racionalidade, na esperança de inspirar reflexões e ações que com o tempo possibilitem mudanças estruturais dentro da prática e da pesquisa em design.

\section{Referências}

ANUSAS, Mike; HARKNESS, Rachel. "Different Presents in the Making". In: SMITH, Rachel Charlotte, VANGKILDE, Kasper Tang, KJÆRSGAARD, Mette Gislev, OTTO, Ton, HALSE, Joachim, and BINDER, Thomas. Design Anthropological Futures, 2016. p. 55-69

BONSIEPE, Gui. Design: Como prática de projeto. São Paulo: Blucher, 2012.

ESCOBAR, Arturo. Autonomía y diseño: La realización de lo comunal. 1. ed. Universidad del Cauca: Sello Editorial, 2016.

ESCOBAR, Arturo. Designs for the Pluriverse. Durham and London: Duke Press University, 2018a.

ESCOBAR, Arturo. Sentipensar con la tierra: nuevas lecturas sobre desarrollo, territorio y diferencia. 4. ed. Medellín: Ediciones UNAULA, 2018 b.

IBARRA, Maria Cristina. Aproximaciones a un diseño participativo sentipensante: correspondencias con un colectivo de residencias en Río de Janeiro. In Proceedings of the 16th Participatory Design Conference 2020 - Participation(s) Otherwise - Vol 3 (PDC '20: Vol. 3), June 15-20, 2020, Manizales, Colombia.

INGOLD, Tim. Prologue. In: Search After Method: Sensing, Moving, and Imagining in Anthropological Fieldwork. New York: Berghahn Books; 2020.

MOURA, Mário. O Design que o design não vê. 1. ed. Lisboa: Abril, 2018.

MUNARI, Bruno. Das coisas nascem coisas. São Paulo: Martins Fontes, 1998.

SANTOS, Boaventura de Sousa. Renovar a teoria crítica e reinventar a emancipação social. 1. ed. São Paulo: Boitempo, 2007.

SERPA, Bibiana; PORTELA. Imaira; COSTARD, Mariana, SILVIA, Samia. Politicalpedagogical contributions to participatory design from Paulo Freire. In Proceedings of the 16th Participatory Design Conference 2020 - Participation(s) Otherwise - Volume 2 (PDC '20). Association for Computing Machinery, New York, NY, USA, 170-174. 2020

SMITH, Rachel Charlotte, VANGKILDE, Kasper Tang, KJÆRSGAARD, Mette Gislev, OTTO, Ton, HALSE, Joachim, and BINDER, Thomas. Design Anthropological Futures: exploring emergence, intervention and formation. London; New York: Bloomsbury Academic, 2016. 


\section{Sobre as autoras}

Débora Andrade. Aluna da Graduação do curso de Design da Universidade Federal de Pernambuco e participante do grupo de pesquisa "Design, antropologia e colaboração".

Maria Cristina Ibarra. Professora adjunta do Departamento de Design da Universidade Federal de Pernambuco (Recife). Doutora em Design pela ESDI/UERJ. Com apoio da CAPES, realizou Doutorado Sanduíche na The Royal Danish Academy of Fine Arts em Copenhague (Dinamarca), especificamente no Codesign Research Centre (CODE). Mestre em Design, Inovação e Sustentabilidade pela UEMG. Designer Industrial pela Universidad del Norte (Colômbia) . Líder do Grupo de Pesquisa "Design, antropologia e colaboração".

https://orcid.org/0000-0002-4466-9510 